\title{
Correction to: Nonparametric estimators of survival function under the mixed case interval-censored model with left truncation
}

\section{Pao-Sheng Shen ${ }^{1}$}

Published online: 9 July 2020

○) Springer Science+Business Media, LLC, part of Springer Nature 2020

\section{Correction to: Lifetime Data Analysis (2020) 26:624-637 https://doi.org/10.1007/s10985-020-09493-2}

The original version of this article unfortunately contains mistakes. It has been corrected with this Correction

1. Errors were made in the name of Chappell and reference resources in the abstract of the original publication of the article. The correct version of the author name and references resources are given below:

(i) On page 624, line 4: In the abstract, change "Pan and Chappel (JAMAStat Probab Lett 38:49-57, 1998a, Biometrics 54:1053-1060, 1998b)" to "Pan and Chappell (Lifetime Data Anal 4: 187-202, 1998b)"

(ii) On page 624, line 12: In the abstract, change "Turnbull's (JAMA 38:290-295, 1976)" to "Turnbull's (JRSS, Ser. B 38:290-295, 1976)"

2. One typing error was made in referring the article "Schick and Yu (2000)". The correction is given below:

On page 626, line 14: Change "Shick and YuSchick and Yu (2000)" to "Schick and Yu (2000)"

3 . Two typing errors were made on left-censoring notation $\delta_{1 i}$, which was mistyped as $\delta_{i}$ in the original publication. The corrections are given below.

(i) On page 631, line 13: Change equation

$$
\hat{L}_{n}^{*}(S)=\prod_{i: \delta_{i}=1}^{n} \frac{S\left(\hat{L}_{i}-\right)-S\left(R_{i}\right)}{S\left(V_{i}-\right)} \times \prod_{i: \delta_{i} \neq 1}^{n} \frac{S\left(L_{i}\right)-S\left(R_{i}\right)}{S\left(V_{i}-\right)}
$$

The original article can be found online at https://doi.org/10.1007/s10985-020-09493-2.

$凶 \quad$ Pao-Sheng Shen

psshen@thu.edu.tw

1 Department of Statistics, Tunghai University, Xitun District, Taichung 40704, Taiwan, ROC 
to

$$
\hat{L}_{n}^{*}(S)=\prod_{i: \delta_{i 1}=1}^{n} \frac{S\left(\hat{L}_{i}-\right)-S\left(R_{i}\right)}{S\left(V_{i}-\right)} \times \prod_{i: \delta_{i 1} \neq 1}^{n} \frac{S\left(L_{i}\right)-S\left(R_{i}\right)}{S\left(V_{i}-\right)}
$$

(ii) On page 631, line 18: Change " $\hat{\mathcal{L}}=\left\{L_{i}: \delta_{i} \neq 1 ; i=1, \ldots, n\right\} \cup\left\{\hat{L}_{i}: \delta_{i}=1 ; i=\right.$ $1, \ldots, n\}$ " to " $\hat{\mathcal{L}}=\left\{L_{i}: \delta_{i 1} \neq 1 ; i=1, \ldots, n\right\} \cup\left\{\hat{L}_{i}: \delta_{i 1}=1 ; i=1, \ldots, n\right\}$ ".

Publisher's Note Springer Nature remains neutral with regard to jurisdictional claims in published maps and institutional affiliations. 